\title{
TWO FIXED-POINT THEOREMS FOR MAPPINGS SATISFYING A GENERAL CONTRACTIVE CONDITION OF INTEGRAL TYPE
}

\section{B. E. RHOADES}

\author{
Received 6 August 2002
}

\begin{abstract}
We establish two fixed-point theorems for mappings satisfying a general contractive inequality of integral type. These results substantially extend the theorem of Branciari (2002).
\end{abstract}

2000 Mathematics Subject Classification: 47H10.

In a recent paper [1], Branciari established the following theorem.

THEOREM 1. Let $(X, d)$ be a complete metric space, $c \in[0,1), f: X \rightarrow X a$ mapping such that, for each $x, y \in X$,

$$
\int_{0}^{d(f x, f y)} \varphi(t) d t \leq c \int_{0}^{d(x, y)} \varphi(t) d t
$$

where $\varphi: \mathbb{R}^{+} \rightarrow \mathbb{R}^{+}$is a Lebesgue-integrable mapping which is summable, nonnegative, and such that, for each $\epsilon>0, \int_{0}^{\epsilon} \varphi(t) d t>0$. Then $f$ has a unique fixed point $z \in X$ such that, for each $x \in X, \lim _{n} f^{n} x=z$.

In [1], it was mentioned that (1) could be extended to more general contractive conditions. It is the purpose of this paper to make such an extension to two of the most general contractive conditions.

Define

$$
m(x, y)=\max \left\{d(x, y), d(x, f x), d(y, f y),\left[\frac{d(x, f y)+d(y, f x)}{2}\right]\right\} .
$$

Our first result is the following theorem.

THeOrem 2. Let $(X, d)$ be a complete metric space, $k \in[0,1), f: X \rightarrow X a$ mapping such that, for each $x, y \in X$,

$$
\int_{0}^{d(f x, f y)} \varphi(t) d t \leq k \int_{0}^{m(x, y)} \varphi(t) d t
$$


where $\varphi: \mathbb{R}^{+} \rightarrow \mathbb{R}^{+}$is a Lebesgue-integrable mapping which is summable, nonnegative, and such that

$$
\int_{0}^{\epsilon} \varphi(t) d t>0 \text { for each } \epsilon>0
$$

Then $f$ has a unique fixed point $z \in X$ and, for each $x \in X, \lim _{n} f^{n} x=z$.

Proof. Let $x \in X$ and, for brevity, define $x_{n}=f^{n} x$. For each integer $n \geq 1$, from (3),

$$
\int_{0}^{d\left(x_{n}, x_{n+1}\right)} \varphi(t) d t \leq k \int_{0}^{m\left(x_{n-1}, x_{n}\right)} \varphi(t) d t .
$$

Using (2),

$$
m\left(x_{n-1}, x_{n}\right)=\max \left\{d\left(x_{n-1}, x_{n}\right), d\left(x_{n}, x_{n+1}\right), \frac{d\left(x_{n-1}, x_{n+1}\right)}{2}\right\} .
$$

But

$$
\begin{aligned}
\frac{d\left(x_{n-1}, x_{n+1}\right)}{2} & \leq \frac{d\left(x_{n-1}, x_{n}\right)+d\left(x_{n}, x_{n+1}\right)}{2} \\
& \leq \max \left\{d\left(x_{n-1}, x_{n}\right), d\left(x_{n}, x_{n+1}\right)\right\}
\end{aligned}
$$

Therefore,

$$
m\left(x_{n-1}, x_{n}\right)=\max \left\{d\left(x_{n-1}, x_{n}\right), d\left(x_{n}, x_{n+1}\right)\right\}
$$

Substituting into (5), one obtains

$$
\begin{aligned}
\int_{0}^{d\left(x_{n}, x_{n+1}\right)} \varphi(t) d t & \leq k \int_{0}^{\max \left\{d\left(x_{n}, x_{n+1}\right), d\left(x_{n-1}, x_{n}\right)\right\}} \varphi(t) d t \\
& =k \max \left\{\int_{0}^{d\left(x_{n}, x_{n+1}\right)} \varphi(t) d t, \int_{0}^{d\left(x_{n-1}, x_{n}\right)} \varphi(t) d t\right\} \\
& =k \int_{0}^{d\left(x_{n-1}, x_{n}\right)} \varphi(t) d t \leq \cdots \leq k^{n} \int_{0}^{d\left(x_{0}, x_{1}\right)} \varphi(t) d t .
\end{aligned}
$$

Taking the limit of (9), as $n \rightarrow \infty$, gives

$$
\lim _{n} \int_{0}^{d\left(x_{n}, x_{n+1}\right)} \varphi(t) d t=0,
$$

which, from (4), implies that

$$
\lim _{n} d\left(x_{n}, x_{n+1}\right)=0 .
$$


We now show that $\left\{x_{n}\right\}$ is Cauchy. Suppose that it is not. Then there exists an $\epsilon>0$ and subsequences $\{m(p)\}$ and $\{n(p)\}$ such that $m(p)<n(p)<$ $m(p+1)$ with

$$
d\left(x_{m(p)}, x_{n(p)}\right) \geq \epsilon, \quad d\left(x_{m(p)}, x_{n(p)-1}\right)<\epsilon .
$$

From (2),

$$
\begin{aligned}
n\left(x_{m(p)-1}, x_{n(p)-1}\right) & \\
=\max & \left\{d\left(x_{m(p)-1}, x_{n(p)-1}\right), d\left(x_{n(p)-1}, x_{m(p)}\right), d\left(x_{n(p)-1}, x_{n(p)}\right),\right. \\
& \left.\frac{d\left(x_{m(p)-1}, x_{n(p)}\right)+d\left(x_{n(p)-1}, x_{m(p)}\right)}{2}\right\} .
\end{aligned}
$$

Using (11),

$$
\lim _{p} \int_{0}^{d\left(x_{m(p)-1}, x_{m(p)}\right)} \varphi(t) d t=\lim _{p} \int_{0}^{d\left(x_{n(p)-1}, x_{n(p)}\right)} \varphi(t) d t=0 .
$$

Using the triangular inequality and (12),

$$
\begin{aligned}
d\left(x_{m(p)-1}, x_{n(p)-1}\right) & \leq d\left(x_{m(p)-1}, x_{m(p)}\right)+d\left(x_{m(p)}, x_{n(p)-1}\right) \\
& <d\left(x_{m(p)-1}, x_{m(p)}\right)+\epsilon .
\end{aligned}
$$

Hence,

$$
\lim _{p} \int_{0}^{d\left(x_{m(p)-1}, x_{n(p)-1}\right)} \varphi(t) d t \leq \int_{0}^{\epsilon} \varphi(t) d t
$$

Using the triangular inequality and (12),

$$
\begin{aligned}
v(m, n) & :=\frac{d\left(x_{m(p)-1}, x_{n(p)}\right)+d\left(x_{n(p)-1}, x_{m(p)}\right)}{2} \\
& \leq \frac{d\left(x_{m(p)-1}, x_{m(p)}\right)+2 d\left(x_{m(p)}, x_{n(p)-1}\right)+d\left(x_{n(p)-1}, x_{n(p)}\right)}{2} \\
& <\frac{d\left(x_{m(p)-1}, x_{m(p)}\right)+d\left(x_{n(p)-1}, x_{n(p)}\right)}{2}+\epsilon .
\end{aligned}
$$

Therefore, using (11),

$$
\lim _{p} \int_{0}^{v(m, n)} \varphi(t) d t \leq \int_{0}^{\epsilon} \varphi(t) d t .
$$

Using (3), (12), (13), (14), (16), and (18), it then follows that

$$
\begin{aligned}
\int_{0}^{\epsilon} \varphi(t) d t & \leq \int_{0}^{d\left(x_{m(p)}, x_{n(p)}\right)} \varphi(t) d t \\
& \leq k \int_{0}^{m\left(x_{m(p)-1}, x_{n(p)-1}\right)} \varphi(t) d t \leq k \int_{0}^{\epsilon} \varphi(t) d t
\end{aligned}
$$


which is a contradiction. Therefore, $\left\{x_{n}\right\}$ is Cauchy, hence convergent. Call the limit $z$.

From (2),

$$
\begin{aligned}
\int_{0}^{d\left(f z, x_{n+1}\right)} \varphi(t) d t & \leq k \int_{0}^{m\left(z, x_{n}\right)} \varphi(t) d t \\
& =k \max \left\{\int_{0}^{d\left(z, x_{n}\right)} \varphi(t) d t, \int_{0}^{d(z, f z)} \varphi(t) d t,\right. \\
& \int_{0}^{d\left(x_{n}, x_{n+1}\right)} \varphi(t) d t, \int_{0}^{d\left(z, x_{n+1}\right)} \varphi(t) d t, \\
& \left.\int_{0}^{d\left(x_{n}, f z\right)} \varphi(t) d t\right\} .
\end{aligned}
$$

Taking the limit of (20) as $n \rightarrow \infty$, one obtains

$$
\int_{0}^{d(f z, z)} \varphi(t) d t \leq k \int_{0}^{d(f z, z)} \varphi(t) d t
$$

which implies that

$$
\int_{0}^{d(f z, z)} \varphi(t) d t=0
$$

which, from (4), implies that $d(z, f z)=0$ or $z=f z$.

Suppose that $z$ and $w$ are fixed points of $f$.

Then, from (2),

$$
\begin{aligned}
\int_{0}^{d(z, w)} \varphi(t) d t & =\int_{0}^{d(f z, f w)} \varphi(t) d t \leq k \int_{0}^{m(z, w)} \varphi(t) d t \\
& =k \max \left\{\int_{0}^{d(z, w)} \varphi(t) d t, 0\right\}=k \int_{0}^{d(z, w)} \varphi(t) d t,
\end{aligned}
$$

which implies that

$$
\int_{0}^{d(z, w)} \varphi(t) d t=0
$$

which, from (4), implies that $d(z, w)=0$, or $z=w$, and the fixed point is unique.

One would like to be able to replace (2) with the integral form of Ćirić's condition [3], that is,

$$
\int_{0}^{d(f x, f y)} \varphi(t) d t \leq k \int_{0}^{M(x, y)} \varphi(t) d t,
$$

where

$$
M(x, y):=\max \{d(x, y), d(x, f x), d(y, f y), d(x, f y), d(y, f x)\} .
$$


But this is not possible since, as the following example shows, one must assume that the orbits are bounded.

EXAMPLE 3. Let $f: \mathbb{N} \rightarrow \mathbb{N}$ be defined by $f(n)=n+1$ and $\phi, \varphi:[0, \infty) \rightarrow$ $[0, \infty)$, where $\phi(t):=(t+1)^{t+1}-1$, and $\varphi(t)=\phi^{\prime}(t)$.

Then, for $n>m$,

$$
\begin{aligned}
M(n, m) & =\max \{n-m, 1, n-m-1, n-m+1\} \\
& =n-m+1=t+1
\end{aligned}
$$

where $t:=n-m$.

Note that, for any $t \in \mathbb{N}$,

$$
\begin{aligned}
(t+2)^{t+2}-1 & =(t+1+1)^{t+2}-1 \geq(t+1)^{t+2}+1^{t+2}-1 \\
& =(t+1)^{t+1}(t+1) \geq 2(t+1)^{t+1} \\
& \geq 2(t+1)^{t+1}-2=2\left[(t+1)^{t+1}-1\right] .
\end{aligned}
$$

Since $\varphi(t)=\phi^{\prime}(t)$, it follows from (28) that

$$
\int_{0}^{t} \varphi(t) d t \leq \frac{1}{2} \int_{0}^{t+1} \varphi(t) d t
$$

or, equivalently,

$$
\int_{0}^{d(f n, f m)} \varphi(t) d t \leq \frac{1}{2} \int_{0}^{M(n, m)} \varphi(t) d t
$$

and (25) is satisfied. However, the orbits are not bounded and $f$ has no fixed points.

Theorem 1 is clearly a special case of Theorem 2 . With $\varphi$ equal to the constant function 1, Theorem 2 reduces to [2, Theorem 2.5]

It is possible to prove a weaker theorem involving condition (25).

Let $O(x, n):=\left\{x, f x, f^{2} x, \ldots, f^{n} x\right\}$. Then $O(x, n)$ is called the $n$th orbit of $x$. For any set $A, \delta(A)$ will denote the diameter of $A$.

THeOrem 4. Let $(X, d)$ be a complete metric space, $k \in[0,1), f: X \rightarrow X a$ mapping such that, for each $x, y \in X$, (25) is satisfied, where $\varphi: \mathbb{R}^{+} \rightarrow \mathbb{R}^{+}$is a Lebesgue-integrable mapping which is summable, nonnegative, and satisfies (4). If there exists a point $x \in X$ with bounded orbit, then $f$ has a unique fixed point $z \in X$.

Proof. From the definition of $O(x, n)$, there exist integers $i, j$ satisfying $0 \leq i<j \leq n$ such that $\delta(O(x, n))=d\left(f^{i} x, f^{j} x\right)$.

ClaIm 5. For some integer $k$ satisfying $0<k \leq n, \delta(O(x, n))=d\left(x, f^{k} x\right)$. 
Proof of Claim 5. We may assume that $\delta(O(x, n))>0$ for each $n$, since, if there exists an $n$ for which $\delta(O(x, n))=0$, then $f$ has a fixed point.

Suppose that $\delta(O(x, n))=d\left(x_{i}, x_{j}\right)$, where $0<i<j \leq n$. Then, from (25),

$$
\begin{aligned}
\int_{0}^{\delta(O(x, n))} \varphi(t) d t & =\int_{0}^{d\left(x_{i}, x_{j}\right)} \varphi(t) d t \leq k \int_{0}^{M\left(x_{i-1}, x_{j-1}\right)} \varphi(t) d t \\
& \leq k \int_{0}^{\delta(O(x, n))} \varphi(t) d t
\end{aligned}
$$

which is a contradiction since $\delta(O(x, n))>0$. Therefore $i=0$.

Pick an $x \in X$ with bounded orbit. Let $m$ and $n$ be integers with $m>n$. Then, from (25),

$$
\begin{aligned}
& \int_{0}^{d\left(x_{n}, x_{m}\right)} \varphi(t) d t \\
& \quad \leq k \int_{0}^{M\left(x_{n-1}, x_{m-1}\right)} \varphi(t) d t \leq k \int_{0}^{\delta\left(O\left(x_{n-1}, m-n+1\right)\right)} \varphi(t) d t \\
& \quad=k \int_{0}^{d\left(x_{n-1}, x_{k_{1}+n-1}\right)} \varphi(t) d t \quad \text { for some } 0<k_{1} \leq m-n+1 \\
& \quad \leq k^{2} \int_{0}^{\delta\left(O\left(x_{n-2}, k_{1}+n-1\right)\right)} \varphi(t) d t \\
& \quad=k^{2} \int_{0}^{d\left(x_{n-2}, x_{\left.k_{2}+n-2\right)}\right)} \varphi(t) d t \quad \text { for some } 0<k_{2} \leq m-n+2 \\
& \quad \vdots \\
& \quad \leq k^{n} \int_{0}^{\delta(O(x, m))} \varphi(t) d t .
\end{aligned}
$$

Taking the limit as $m, n \rightarrow \infty$ gives, since the orbit of $x$ is bounded,

$$
\lim _{m, n} \int_{0}^{d\left(x_{n}, x_{m}\right)} \varphi(t) d t=0
$$

which, from (4), implies that

$$
\lim _{m, n} d\left(x_{n}, x_{m}\right)=0
$$

Thus $\left\{x_{n}\right\}$ is Cauchy, hence convergent. Call the limit $z$. From (25),

$$
\begin{aligned}
\int_{0}^{d\left(x_{n+1}, f z\right)} \varphi(t) d t & \leq k \int_{0}^{M\left(x_{n}, z\right)} \varphi(t) d t \\
& =k \int_{0}^{\max \left\{d\left(x_{n}, z\right), d\left(x_{n}, x_{n+1}\right), d(z, f z), d\left(x_{n}, f z\right), d\left(z, x_{n+1}\right)\right\}} \varphi(t) d t .
\end{aligned}
$$


Taking the limit of both sides, as $n \rightarrow \infty$, gives

$$
\int_{0}^{d(z, f z)} \varphi(t) d t \leq k \int_{0}^{d(z, f z)} \varphi(t) d t,
$$

which implies that $d(z, f z)=0$, which, from (4), implies that $z=f z$.

Suppose that $z$ and $w$ are fixed points of $f$. From (25),

$$
\int_{0}^{d(z, w)} \varphi(t) d t \leq k \int_{0}^{d(z, w)} \varphi(t) d t,
$$

which implies that $z=w$, and the fixed point is unique.

The following example shows that (2) is indeed a proper extension of (1).

EXAMPLE 6. Let $X:=\{1 / n: n \in \mathbb{Z},|n| \geq 2\} \cup\{0\}$ endowed with the Euclidean metric. Define $f: X \rightarrow X$ by

$$
f\left(\frac{1}{n}\right):= \begin{cases}\frac{1}{n+1}, & n>1 \text { and odd, } \\ \frac{1}{n}, & n>0 \text { and even or } n<-1 \text { and odd, } \\ \frac{1}{n+1}, & n<0 \text { and even, } \\ 0, & n=\infty .\end{cases}
$$

Acknowledgment. The author wishes to thank the referee for careful reading of the original manuscript and for providing Examples 3 and 6 .

\section{REFERENCES}

[1] A. Branciari, A fixed point theorem for mappings satisfying a general contractive condition of integral type, Int. J. Math. Math. Sci. 29 (2002), no. 9, 531-536.

[2] Lj. B. Ćirić, Generalized contractions and fixed-point theorems, Publ. Inst. Math. (Beograd) (N.S.) 12(26) (1971), 19-26.

[3] _ A generalization of Banach's contraction principle, Proc. Amer. Math. Soc. 45 (1974), 267-273.

B. E. Rhoades: Department of Mathematics, Indiana University, Bloomington, IN 47405-7106, USA

E-mail address: rhoades@indiana.edu 


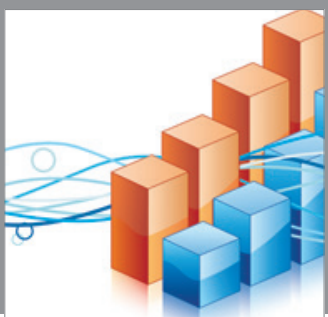

Advances in

Operations Research

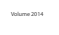

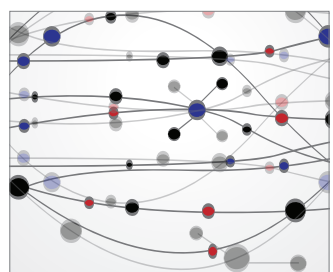

\section{The Scientific} World Journal
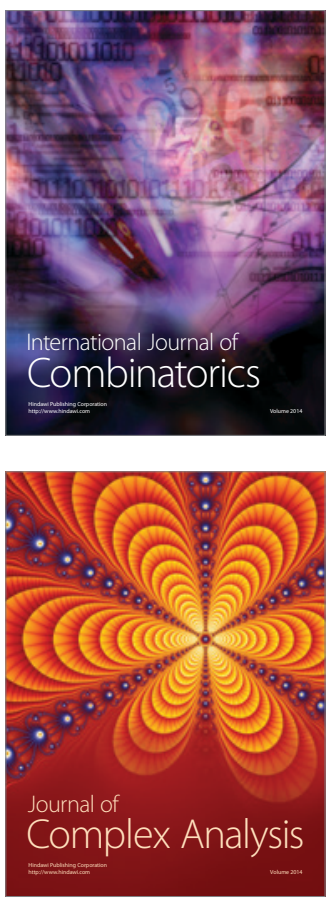

International Journal of

Mathematics and

Mathematical

Sciences
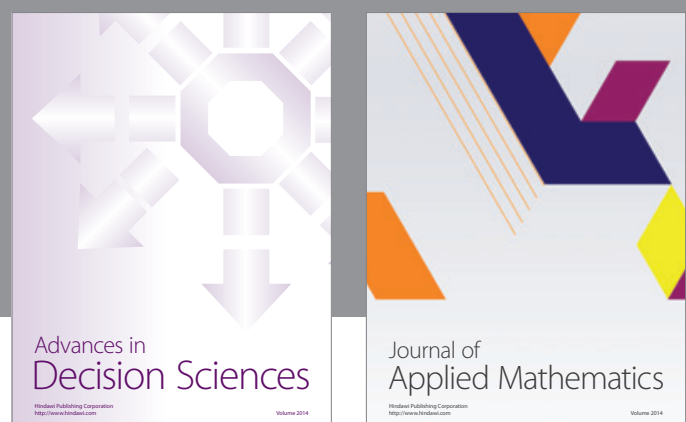

Journal of

Applied Mathematics
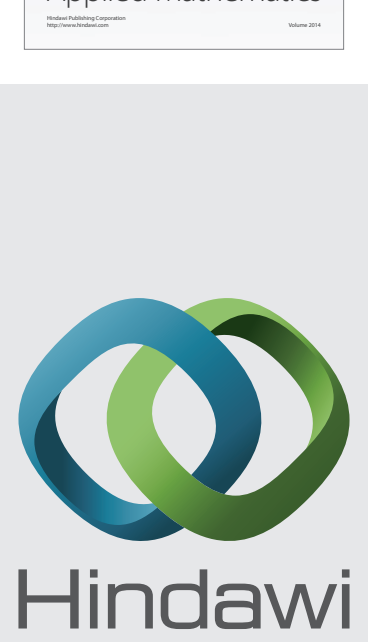

Submit your manuscripts at http://www.hindawi.com
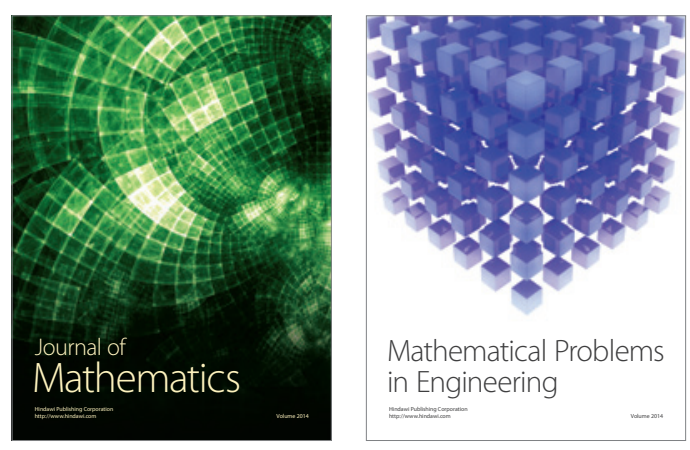

Mathematical Problems in Engineering
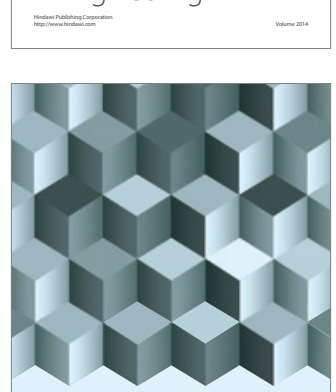

Journal of

Function Spaces
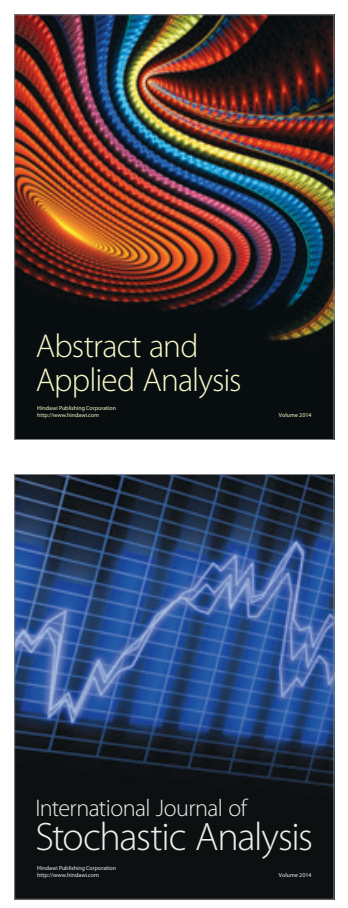

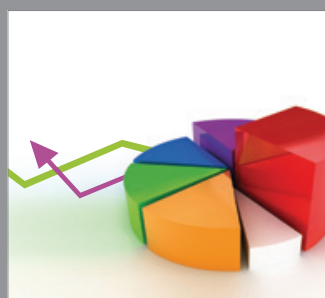

ournal of

Probability and Statistics

Promensencen
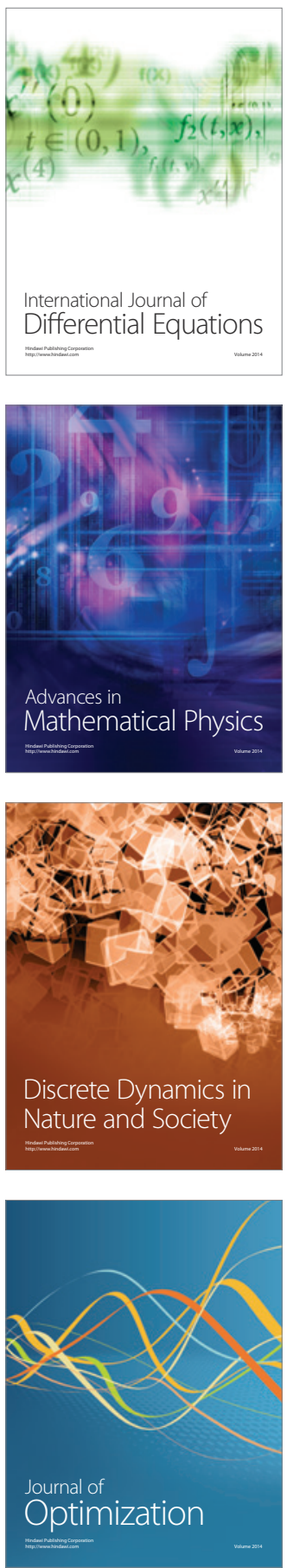